\title{
The Polycentric Leadership Model - A Circular and Decentralized Approach to Leadership Sociology
}

\author{
Luigi Gentili
}

\section{ABSTRACT}

\begin{abstract}
This paper introduces a new leadership model. Staring with the examination of the concept of leadership, leaders' core skills and the differences between various management definitions, the paper highlights what organizational conditions are needed for leadership to be effective and successful. The results of a sociological study show that leadership always promotes change and involvement. It creates social cohesion and sets a clear direction. The paper focuses on these results to present the "matrix of Polycentric Leadership". Thanks to this matrix, we can identify four leadership styles: methodical, directive, charismatic, and challenger. The paper concludes that leadership cannot be effective if just one or few of these styles are present: all four styles must be represented, as they are complementary and interact with each other, ensuring the unifying function of leadership. To conclude, the paper demonstrates that leadership is always a polycentric phenomenon that takes place via a network of relations between these four leadership styles. When the interaction does not take place, leadership degenerates, and the shadows of these leadership styles' take over.
\end{abstract}

Keywords: Charisma, Leadership, Leadership development, Neurotic leadership.

\author{
Submitted : June 23, 2021 \\ Published : August 16, 2021 \\ ISSN: $2507-1076$ \\ DOI: $10.24018 /$ ejbmr.2021.6.4.990 \\ Luigi Gentili* \\ CEIMA. Centro Studi per l'Innovazione \\ Manageriale (Centre for the Study of \\ Managerial Innovation), Rome, Italy. \\ (e-mail: luigi.gentili@ ceima.eu)
}

*Corresponding Author

\section{INTRODUCTION}

The definition of leadership has evolved. The concept of a leader at the top of a hierarchical pyramid that would lead single-handedly an organization has become obsolete. Continual innovation due to global relations, rapid technological innovation, political disruption, and social shifts [1] highlight that direction, purpose and momentum cannot be generated and sustained solely by an individual and many organizations are adapting by creating shared responsibilities to meet increasing levels of task interdependence [2]. Plural leadership improves team effectiveness and performance and is an important enabler of new venture development and growth [3], [4].

Leadership influences the member of an organization by creating a narrative, on-going conversations, social interaction, organizational practices, and emergent processes [5]. In chaotic global environments, leadership terms can be linked to dynamism, relationship, and systemic influence [6]. Leadership is central to support the collaborative development of an organization: hence why it's important to embrace disruption with clarity of purpose and resilience, while connecting people, relating to others on a human level and seeking creative and innovative possibility [7].

Plural leadership can be identified and defined through a biographical sociology study of a sample of universally recognised leaders, considering only their shared characteristics. Sources cited include papers and books. In this sample we will examine business leaders who belong to highly innovative organizations and political leaders known for their civil movement's activism. The selected leaders, chosen because they are considered representative of successful leadership, are Wilbert "Bill" L. Gore of W. L. Gore \& Associates, Richard Branson of Virgin Group, Percy Barnevik of ABB, Martin Luther King, Mahatma Gandhi and Nelson Mandela.

The examination of common traits of leaders from both business and political contexts, allows us to identify core leadership skills and social dynamics.

All the leaders selected are master in guiding others. Leaders show a direction and indicate the others a path to follow. People are always free so that they will follow the leader willingly. They can leave the leader at any moment, with no constraints. For this reason, leadership is different from any other form of power, among which we can find bossing. Bossing is a type of unidirectional power, intimidating and coercive - a kind of command. It uses a topdown approach, with vertical communication. Leadership, instead, has a multidirectional nature, encouraging lateral communication. For example, Bill Gore promotes a company culture where employees can communicate directly, without intermediate management level [8]-[12].

Power always has two faces: one negative and one positive. More precisely, to command means to practice a form of negative power; on the contrary, to lead means to practice a form of positive power. Leaders mentioned in this paper inspire the followers, ignite passion, create enthusiasm and dedication. They show a coherent future direction, making sense of shared purpose. Leaders exercise a positive power 
because they attract others by instilling hope. Martin Luther King and Gandhi wanted a new society, without discrimination: the practice of nonviolence has caused many people to follow them [13]-[19].

The context where the leadership acts is crucial. Leaders need an open and dynamic working environment. Leadership does not work formally inside rigid bureaucracies: its nature is relational. In bureaucracies' leaders act informally, through their network of personal relationships, out of the official channels. That is because leadership creates an emotional commitment with the followers. True leaders knit invisible bonds. Mandela, for example, exercised his influence even when he was in prison [20]-[22].

Interactions with followers can be direct or indirect. The indirect interactions take place with sub-leaders. This dynamic constitutes a second-level of leadership: a power practised through an interposed layer of people. For this reason, we can find different levels of leadership. There are team leaders, organizational leaders, and context leaders. In the first case, bonds between leaders and followers are direct; they are indirect in the other two cases. This is a crucial element to understand the power that a leader can exert. Leadership performance is based on network interactions, inside and outside an organization. Leadership cannot be described without analysing the social network interactions in which it operates.

The study of enterprise networks becomes significant, and leadership is necessary now more than ever. With the economic globalisation, organizational structures become disarticulated and fragmented. The best companies are organised as a network: they become a web of links. The competitive advantage of enterprises is related to the ability to create synergy, and the success of the management depends on the horizontal organizational structures. The companies started by Branson and Barnevik, for example, have a flat structure, with small autonomous units run by self-managed teams. Their structure is adapted to building interorganizational alliances too [23]-[27].

Leadership is essential to direct organizational networks. The leadership's power is based on a mutual exchange, i.e., developing relationships among different actors belonging to an organizational net. Leadership creates connivance, solidarity, and participation, with personal and social skills. Indeed, leaders must know how to manage themselves in harmony with others, solving problems and making decisions. Through the interpersonal influence, leaders build bridges and demolish walls. These considerations make it possible to identify the core leadership skills.

\section{CORE LEADERSHIP SKILLS AND SOCIAL DYNAMICS}

Twenty-two of the most common skills in roles of organizational responsibilities are identified in this research (Table I).

The skills attributed to leadership, common to all of the six leaders used in this research, are the following: active listening, reliability, empowerment, assertiveness, initiative, adaptability, forecasting, commitment, integrity and perseverance. Not all of them possess the remaining twelve skills. They are competencies possessed only by the three business leaders and they are attributed to management roles.
These are: make plan, align to business goals, manage performance, service coordination, project integration, budgeting, supervising others, coaching, schedule tasks, quality results orientation, controlling, customer support.

TABLE I: COMPARATIVE ANALYSIS OF LEADERSHIP SKILLS

\begin{tabular}{ll}
\hline 1. Active listening & 12. Supervising others \\
2. Make plan & 13. Coaching \\
3. Align to business goals & 14. Adaptability \\
4. Integrity & 15. Schedule tasks \\
5. Manage performance & 16. Reliability \\
6. Initiative & 17. Quality results orientation \\
7. Perseverance & 18. Controlling \\
8. Service coordination & 19. Empowerment \\
9. Commitment & 20. Assertiveness \\
10. Project integration & 21. Customer support \\
11. Budgeting & 22. Forecasting \\
\hline
\end{tabular}

The first list contains "soft skills", directly relevant to the practice of leadership functions. The main characteristic of these skills is that they act on behaviours. Leaders don't use rules and regulations, instructions, and controls procedures. Leadership always focuses on people, relationship, and connectedness [28], [29]. This concept provides us with the difference between leadership and management. These two terms are often used as synonyms, but their meanings are different both in theory and practice [30]. Managers, indeed, are regarded as following rules. They have formal authority, vested in them by an organization, and their subordinates work for them because they have been promised a reward. Managers show emotional distance, expert mind, conformity, and insight into the company

According to Abraham Zalenznik [31], leaders are like artists who use creativity and intuition to navigate through the chaos while managers, on the contrary, seek rationality, control, and order. Warren Bennis and Burt Nanus [32], instead, suggests that managers "do things right" while leaders do "the right thing". These definitions express well the difference between the two conceptions of corporate power. Managers specify objectives which should be attained and check on the result achieved. Leaders, on the contrary, communicate the vision, the mission, and the values to pursue. Managers use numbers and work in the economy field; instead, leaders use symbols and work in the culture field. A manager uses "hard skills" while leaders use "soft skills". They use different competencies, but their roles are complementary. There are managers with leadership skills and leaders with management skills. Bill Gore, Branson and Barnevik belong to the second category.

The two social dynamics that are connected to the core skills of leadership and allow it to exercise it are change and involvement. In reaching this conclusion, the following social dynamics were analysed: social change, professionalisation of followers, social involvement, functional articulation of work, rationalization of production, maximisation of performance (Table II).

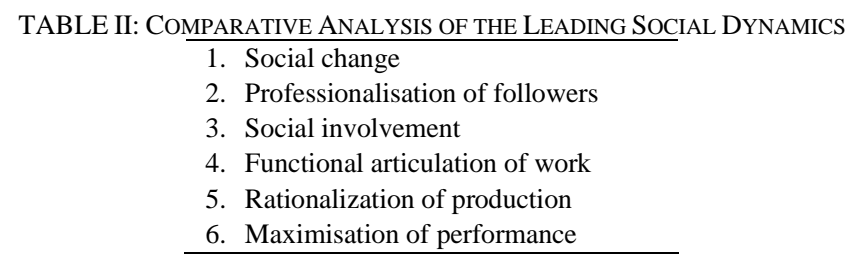

Only change and involvement dynamics were common to all six leaders used in this research. The other dynamics were 
found only among the business leaders, and they are dynamic that can be attributed only to management.

\section{A POLYCENTRIC APPROACH TO LEADERSHIP}

Leaders provide direction and unite people. Through collective interaction, they create simultaneously change and involvement. Leaders encourage change by promoting a new perspective for the future. At the same time, leaders involve people by fostering participation and cohesion. Change and involvement, however, are of two kinds. Change can be incremental or radical: in the first case, change is slow and partial, while in the second case, it is fast, sudden, and total. Involvement can be, instead, restricted, or extensive: in the first case, involvement concerns only one group, while in the second case, it involves a broader community, formed by different groups interconnected.

Entering the two variables in a cartesian plane, change and involvement - and their dual differentiation - we have polycentric leadership matrix. This name depends on the fact that there is no single leader but a plurality of them. In the organizational environment, there are many different leaders, interacting reciprocally. The matrix shows a dialectical approach to leadership: in fact, there is a continuing restructuring of the organizational practice. Polycentric leadership always moves beyond conflicting interests, becoming the expression of a corporate process.

In Figure 1 the variable "change" is located on the vertical axis, while the variable "involvement" is located on the horizontal axis.

On the graph, we can observe that four leadership styles emerge: methodical, directive, challenger and charismatic.

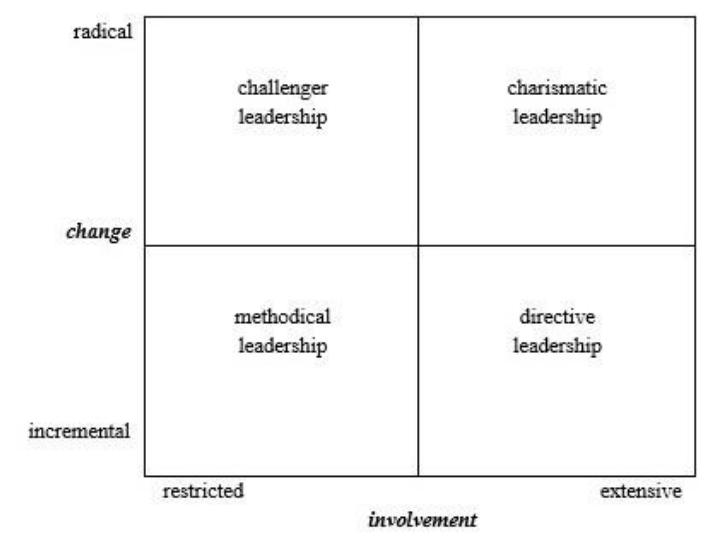

Fig. 1. The matrix of polycentric leadership.

Methodical leadership emerges from the intersection of an incremental change and a restricted involvement. It is a moderate style, practised on limited groups with a gradual action. Methodical leaders are widespread, and for this reason, they often pass unnoticed. Generally, they are subleader and act in a stable context. Two examples may be the following: a) the middle manager of a big industry; b) the responsible for a section of a party. Directive leadership, instead, emerges from the intersection between an incremental change and an enlarged involvement. Similarly, to the methodical one, directive leadership acts slowly, day by day, but it involves a whole organization. It is essential to guide methodical sub-leaders, that would be otherwise disoriented and inconsistent. Two examples of directive leaders are the following: a) the general director-general of a company: b) the party secretary.

Challenger leadership emerges from the intersection between a radical change and a restricted involvement. Challenger leaders are not numerous. They are sub-leaders which promote in a limited group a process of fast transformation. Two examples may be the following: a) the manager that introduces a new product in the market; b) the municipal councillor that deals with a particular problem in an urban district. Charismatic leadership, instead, emerges from the intersection of a radical change and an enlarged involvement. It calls into question the status quo, suddenly. Charismatic leaders guide the challenger sub-leaders to create or restructure an organizational as a whole. The nascent state of a collective organization always starts by a charismatic leader, capable of uniting people and setting up new moral solidarity, alternatively to the existing context. Like a biblical prophet, a charismatic leader says: "It is written, but I say unto you!". Two examples of charismatic leadership may be the following: a) the entrepreneur who launches a new global brand; b) the guru of a religious movement that proposes the coming of a new era.

Examples of leaders, according to the examined typology, are various. They may change in relation to different kinds of social contexts. First of all, it is important to explain the difference between directive and charismatic leaders. The visibility of methodical and challenger leaders is low since they are widespread sub-leaders. The history of creative groups, for example, shows several examples of the directive and charismatic leaders. In the Bauhaus, the famous German art school operational from 1919 to 1933, we can find Johannes Itten as a directive leader and Walter Gropius as a charismatic leader. In the Frankfurt School, during the interwar period, Carl Grunberg was active in the sector of social research as directive leader, while Max Horkheimer was a charismatic leader. In the Manhattan Project at Los Alamos, which researched nuclear physics during World War II, there is Groves as a directive leader and Robert Oppenheimer as a charismatic leader.

The directive and charismatic type of leaders mobilise a wider network of sub-leaders, methodical and challengers, who commit themselves to pursue, to micro-level, what the other leaders provide to the level of general coordination. Sub-leaders are the transmission belt between directive and charismatic leadership and the followers, and they are positioned on multiple levels. Considering the previous research, if we take the three charismatic leaders Bill Gore, Branson and Barnevik, we can find a network of sub-leaders inside their companies. In every organization and in every social context, the four leadership styles are interdependent. Without sub-leaders, directive and charismatic leaders would not be able to act directly on a multitude of people, while without them, sub-leaders won't have a direction.

Methodical and directive leaders act in everyday practice by ensuring the orderly functioning of an organizational system. On the contrary, challenger and charismatic leaders enter action during breakthrough moments, when something extraordinary happens. These can remain latent state during the routine but resurface in times of crisis or a moment of transition. However, some charismatic leaders remain always active: as they reach a goal, for example surmounting an institutional obstacle, they immediately find a new goal and undertake new activities. If they don't find new stimulus in their current context, they may emigrate elsewhere. 
There is not a better leadership style than another. All four styles have equal importance: it is important instead to have them simultaneously in an organization for this to be successful. When this is not possible, these four leadership styles can be present in different organizations, interconnected. The four leadership styles can be present in an organizational network, rather than in one company if they are present in smaller structures. That is why leadership is polycentric. Leadership cannot be undertaken by one person only. Leadership is a pluralist phenomenon based on the interdependence and the integration of more people.

\section{LEADERS IN THE SHADOWS}

The polycentric leadership model can also contribute to explaining the possible leader degeneration. Isolated leaders, indeed, always degenerate, manifesting a form of negative power that produces neurotic organizations. The leaders, in such situations, become the opposite of themselves. Using the language of Jung's psychoanalysis, leaders materialise their shadow.

The concept of shadow refers to that of the archetype. It is developed by Carl Gustav Jung and goes beyond the physiology of Sigmund Freud. According to Jung, apart from the individual unconscious, there is also a collective unconscious: it derivates from the symbolic inheritance of a culture, and its content is impersonal and universal [33]. The following are examples of archetypes: the father: authority figure; the child: a longing for innocence; the hero: champion; the maiden: innocence; the trickster: deceiver.

Even in the model of polycentric leadership, the four typologies of leaders correspond to as many kinds of archetypes. Let's look, for example, at charismatic leadership. This archetype can be observed in different contexts. For instance, using the great reformers' archetype, there are charismatic leaders as Mose, Pericles, Marcus Aurelius, Christopher Columbus, Lincoln, Franklin Roosevelt, John Kennedy and so on. The same applies to the other three styles of leadership.

It's possible to understand then the degenerations of leadership if we look at leadership styles through the archetypes angle. According to Jung, every archetype has its own shadow. The four styles of leadership, as the archetypes, have their own shadow too. The shadows of the leadership styles are the opposite - in negative terms - of their essence. Not all leaders can maintain over time a physical and emotional equilibrium. When they are under stress, leaders can degenerate, showing their shadow characteristics, related to their specific archetype. Potentially, the shadow of a leader is always present but appears only in critical situations. By means to the matrix of polycentric leadership, it is possible to observe that the shadows arise from the relations established among the different leaders.

The shadows which characterise the four styles of leadership are as follows: free rein, authoritarian, subversive, and factious leadership. Methodical leaders can become permissive, directive leaders' authoritarian, charismatic leaders' subversive and challenger leaders factious. Each style of leadership has its way to degenerate power. The process is dynamic and expansive: the transformation begins in one of the four quadrants of the matrix and then extends to the remaining ones. When a leadership style degenerates inside an organization, a negative contagion is created, and leadership is compromised at all levels. This explains the birth of many neurotic organizations. Neurotic organizations are organizations where leadership has degenerated, a victim of its shadows. Fig. 2 shows the dynamic of this process.

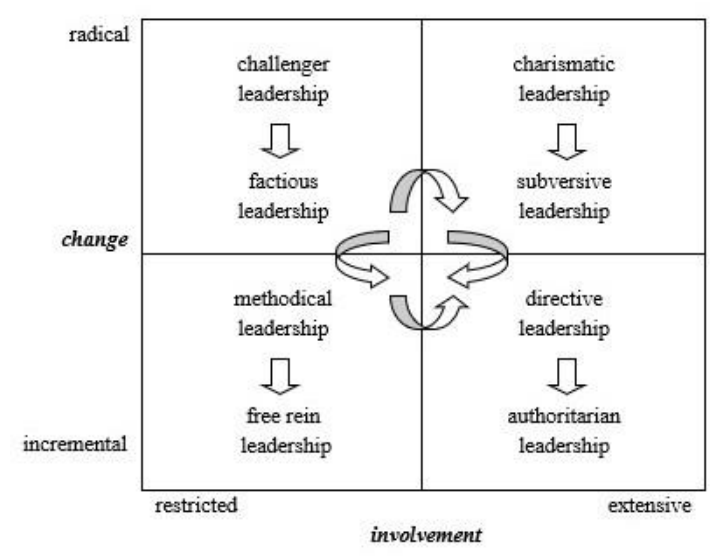

Fig. 2. The shadows of leadership.

Free rein leadership surfaces when methodical leaders no longer interact with the directive ones. In this case, methodical leaders stay relegated to their group of affiliation, losing the spirit of cohesion that holds them together with other groups. The overall coordination ensured by a directive leader - who acts as the glue that binds all groups in an organization - fails. The common action becomes inconclusive and vague.

Instead, authoritarian leadership surfaces when directive leaders, in times of crisis or sudden change, no longer interact with the charismatic ones. In times of transition, charisma is fundamental to devise new ideas and perspectives, in the absence of which people become apathetic and indifferent. Without enthusiasm, spontaneous consent no longer exists. Followers don't listen to the leader, who is forced to become authoritarian. Through this perspective, it's possible to understand the birth of many autocratic regimes. Authoritarian leadership makes building consensus impossible.

Subversive leadership surfaces when charismatic leaders no longer interact with the challenger ones. In this case, charismatic leaders lose contact with the social context of belonging. Challenger leaders are the transmission belt between charismatic leaders and the organization. Without them, a charismatic leader assumes a self-referential behaviour and holds all the power in his/her hands.

Lastly, factious leadership emerges when challenger leaders no longer interact with the methodical ones. In this case, they interrupt direct contact with the activists and methodical sub-leaders' activists. Challenger leaders are always a minority, because society tends to inaction, and all radical processing starts from a very few people. When challengers' leaders' close ranks, they also lose contact with society and form closed and self-referential groups, in conflict with external.

Historically, subversive, and authoritarian leaders have always had greater visibility. Free rein and factious leaders are sub-leaders, and no one remembers them. Maximilien Robespierre or Vladimir Lenin are examples of subversive leaders. Queen Elisabeth I or Otto von Bismarck are instead examples of authoritarian leaders. In the business field, the alternation between subversive and authoritarian leaders are observable in many cases of business failures in history: for 
example, in The Medici Bank, in Company of Scotland or The Company of the West [34].

The shadow of power does not damage the image of a leader immediately. Why is that? Because the image does not degenerate suddenly. Indeed, the shadow of leadership can be functional for short periods, especially when emerging during a sudden emergency. A directive leader, for example, can become authoritarian when a working group shows signs of insubordination. A challenger leader, instead, can become factious if a vertical organization discriminates some of its employees. Degeneration occurs when the shadow of leadership persists in time. Only then there will be free rein, subversive, and factious chiefs.

Leadership is based on interactive relationships - among the leader and the sub-leaders or all the followers, in the case of small groups -, inside a social context which ensures the simultaneous presence of the four styles of influence examined. Only when this interactive and simultaneous relationship is interrupted, leadership degenerates. When and where the break occurs, inside one of the four quadrants examined, the shadow of one leader emerges. For example, the process can begin at the interaction point between methodical and directive leadership, or between charismatic and challenger one, with the related shadows emerging respectively.

If a style of leadership degenerates, all the others, in a cascade process, degenerate accordingly. Every leadership style is essential for others to exist. Individual leadership is just an abstraction. Leaders exist as a phenomenon of élite.

When leadership degenerates, also organizational dynamism stops. Dynamism is the alternation between two particulars of organizational life: the ordinary time and the extraordinary one. The first represents everyday life, the second instead represents extraordinary intervention, in a context of crises or sudden transformation. Methodical and directive leaders act in the first instance, charismatic and challenger leaders act instead during the second one. These two interactives' periods have also their independent living. The interaction between methodical and directive leadership is continuous, while leaders are activated only in contingent need between charismatic and challenger leaders. The interaction between directive leaders and charismatic ones, and between challenger and methodical leaders, is activated only in moments of radical transformation. If this does not happen, the organization flattens on the present, losing his creative momentum and his capacity to adapt.

Not all organizations have all four styles of leaderships among their leaders. In small organizations often, there are not enough leaders to ensure the differences required. What happens then? Some leaders change their style momentarily or, more often, different leaders are co-opted in an organizational network

Sometimes, a leader can change his/her style of influence when particular circumstances require so: a directive leader, for example, can become a charismatic one to direct a sudden corporate merger or a challenger leader can become a methodical one in order to launch a new product on the market. No matter the situation or the style, it is never easy for a leader to change his or her style.

More common is, however, to co-opt a leader from an external organization, hence the importance of the organizational network. When an organization is unable to guarantee the four styles of leadership internally - as sometimes happens in small groups - necessary complementary leaders may be located within other organizations belonging to a network. In this instance, the interaction among the leaders takes place in a complex environment. This is why leaders often are builders of networks. Examples of organizational networks are numerous, and they can be informal or formal. Among the formal networks we can find, for example, the interlocking directorates, the joint ventures, the strategic alliances or spins off.

\section{REVIEW OF RELATED LITERATURE}

There are no other studies giving results similar to those shown in the polycentric leadership model. However, the studies concerning plural leadership seem to be near to the model mentioned. Many articles have been written on plural leadership. Most of them show how leadership is a collective action, a social relationship that facilitates participation, integration and cooperation among people. For this reason, its action cannot be relegated only a unilateral interaction with the followers. Leadership can take place exclusively in a network and its perspective, which includes followers but also other leaders. The interactions between leaders are as important as those between leader-followers. It is a mistake to consider leaders as individuals, and it is impossible to study their characteristics as if he were monads.

James P. Spillane [35] said that leadership practice is defined through the relation of more leaders, with interdependency between their actions. Leadership functions are typically distributed among three to seven people [36], and often involve some combination of four leaders [35]. Jing Zhang and Sue R. Faerman [37] apply instead the concept of plural leadership in current communities of practice: multiple leadership emerges to influence the change process during and after the implementation of the knowledge systems in organizations. Jean-Louis Denis, Ann Langley and Viviane Sergi [38], describe hence the combined influence of multiple leaders in specific professional organizations and interorganizational partnership. According to researchers, plural leadership is a social phenomenon that is distributed or shared among different persons, potentially fluid, and constructed in interaction. Two other contributions from working groups follow. Leroy White, Graeme Currie, and Andy Lockett [39], describe the emergent network of relations in complex organizations. According to these scholars, there is a connection between collective leadership, organizational performance, and informal social network structures. Ken Otter and Doug Paxton [40], argued that collaborative leadership is essential during times of rapid change: their research program emphasises attention to innovation and adaptability for the leadership team.

The models examined highlight a valid contribution to the plural leadership studies, however, they show limitations. Firstly, there is no reference to the complementarity between different leaders acting in harmony. Leaders are always considered interchangeable subjects, with complete and autonomous functions. Furthermore, we cannot find an explanation of the quality of charisma and for the disruptive change behaviour. In these models, leaders act in the present, incrementally, without considering breakthrough innovation and growth. Without the distinction between incremental 
improvement and big breakthrough in performance, we don't have all the elements to understand leadership dysfunction.

\section{CONCLUSION}

Individual leaders are just a myth. Although many scholars believe that there are only individual leaders, the reality is different. Leadership is always a collective entity. To be a leader means to belong to a network of people, among them interdependent and complementary. Leadership is also a dialectical process. When leaders interact among them, transformations continue into the organization, connecting past, present and future. Charismatic leadership enables radical transition. It is a process that concerns the direct relationship between a charismatic leader with other leaders, and not only the extraordinary abilities of an individual. It deals with a circular interaction between different and integrative leaders, active at multiple levels. Some of the leaders move slowly, others quickly, but everyone acts in unison.

Leadership, following the Polycentric Leadership model, is a phenomenon of élite. In this sense, an élite is characterised by the presence of multiple leaders. When it does not happen, when leaders are isolated, an organization degenerate. Leadership fades away, leaving space to its shadows. Without polycentric leadership, any organization becomes neurotic, and command or authority takes its place. Everything stops, and the management of daily life becomes the main concern. Organizations reject change and progress. All organizational events, rather than being governed, are tolerated.

In neurotic organizations, without polycentric leadership, people lack motivation and become apathetic and indifferent. This is why the selection system should be improved, including training and evaluation of human resources. It is necessary to select, to train and to evaluate, simultaneously, different leaders. To be successful, an organization must guarantee a correct mix of leadership styles, to enable growth and competitiveness.

Shortly, in a world of business networks that demand continuous innovation, it will be the understanding and correct application of the Polycentric Leadership model, which will make the difference between failing and succeeding organizations.

\section{REFERENCES}

[1] C. McCauley \& C. J. Palus, "Developing the theory and practice of leadership development: A relational view", The Leadership Quarterly, 2020.

[2] Q. Wu, K. Cormican, G. Chen, "A Meta-Analysis of Shared Leadership: Antecedents, Consequences, and Moderators", Journal of Leadership \& Organizational Studies, 2018

[3] J.H. Karriker, L. T. Madden, L. A. Katell, "Team Composition, Distributed Leadership, and Performance: It's Good to Share", Journal of Leadership \& Organizational Studies, 2017.

[4] Z. Chen, Y. Yu, S. Huang, "How Shared Leadership in Entrepreneurial Teams Influences New Venture Performance: A Moderated Mediation Model”, Journal of Leadership \& Organizational Studies, 2020.

[5] D. Van De Mieroop, J. Clifton \& A. Verhelst, "Investigating the interplay between formal and informal leaders in a shared leadership configuration: A multimodal conversation analytical study", Human Relations, 2019, 73(4), 490-515.
[6] S. S. Ecetin \& S. N. Acikalin Editors, S. N. Acikalin, Chaos complexity and leadership, Cham: Springer, 2018.

[7] E. Sinar et. al., "Global leadership forecast 2018. Developmental Dimensions International", The Conference Board, and Ernst \& Young Global Limited, 2018.

[8] G. Hamel, "Building an innovation democracy: W. L. Gore", in The future of management, Harvard: Business School Press, 2007.

[9] C. C. Manz, F. M. Shipper and G. L. Steward, "Everyone a Team Leader: Shared Influence at W. L. Gore \& Associates", Organizational Dynamics, 2009, 38(3):239-244.

[10] F. M. Schipper and C. C. Manz, "W. L. Gore \& Associates, Inc.: a case study", in Strategic Management: concepts and cases, Irwin, 1999

[11] J. Rao, W. L. Gore-Culture of innovation, Babson, BAB698 April 01, 2012.

[12] M. Cannon, J. Thorpe, S. Emili, P. Mader, "W.L. Gore \& Associates Inc.: Workplace Democracy in a Transnational Corporation”, Business and Financing Models that Enable Participation, Case Summary No. 3 , 2019.

[13] R. Deats, Mahatma Gandhi non violent liberator. A biography, New York, New City, 2005.

[14] M. Gandhi, Autobiography, New York, Dover Publications, 1983.

[15] R. E. Jakoubek, H. L. Wagner, Martin Luther King Jr.: Civil Rights Leader, New York, Chelsea House, 2009.

[16] M. L. King Jr., The word of Martin Luther Jr., New York, William Morrow \& Co, 2007.

[17] S. Dhiman, Gandhi and leadership, New York, Palgrave Macmillan, 2015.

[18] L. Calkhoven, DK Life Stories Martin Luther King Jr., London, Penguin Random House, 2019.

[19] R. Jahanbegloo, Mahatma Gandhi: A Nonviolent Perspective on Peace, Abingdon, Taylor \& Francis Ltd, 2020

[20] K. Magoon, Nelson Mandela: A Leader for Freedom, Edina, ABDO Publishing Company, 2008.

[21] N. Mandela, Long walk to freedom. The autography of Nelson Mandela, Boston, Brown and Company, 1994.

[22] S. Krensky, DK Life Stories Nelson Mandela, London, Penguin Random House, 2019.

[23] R. Branson, Business Stripped Bare, London, Virgin Books Ltd, 2008

[24] D. G. W. Dauphinais, "Creating a federation of nationals cultures. Percy Barnevik", ABB Asea Brown Boveri Ltd., in Straight from the CEO, New York: Price Waterhouse Coopers, 1998.

[25] R. Dick, "Branson's Virgin The coming of Age of a counter-Cultural Enterprise", Fontainebleau, INSEAD Case Study, 1995

[26] F. R. M. Kets de Vries, "Charisma in action", Organizational Dynamics, Winter, 1998

[27] N. Champroux (2014) "Richard Branson, Virgin's Embedded Entrepreneur. Frankfurt", World Business History Conference.

[28] M. Liphadzi, C. O. Aigbavboa \& W. D. Thwala, "A Theoretical Perspective on the Difference between Leadership and Management", Procedia Engineering, 196478 - 482, 2014.

[29] B. N. Wajdy, "The differences between management and leadership", Sinergi, Volume 7, No 1., 2017.

[30] P. Ellis \& J. Abbott, "Are leadership and management different?", Journal of Kidney Care, 5(1), 45-47, 2020.

[31] A. Zaleznik, "Managers and leaders: are they different?", Boston, Harvard Business Review, May-June, 1977

[32] W. Bennis and B. Nanus, in the work cited, 1985.

[33] C. G. Jung, The archetypes and the collective unconscious, New York, Princeton University Press, 1969 [1934]

[34] A. Cain, "6 of the most spectacular business failures in history", Insider, Nov. 7, 2016.

[35] J. P. Spillane, "Distributed leadership", The Educational Forum, 69(2), $143-150,2005$

[36] E. M. Camburn, B. Rowan and J. Taylor, "Distributed leadership in school: the case of elementary schools adopting comprehensive school reform models", Educational Evaluation and Policy Analysis, 25(4); 347-73, 2003.

[37] J. Zhang, S. R. Faerman, R. Sue, "Distributed leadership in the development of a knowledge sharing system", European Journal of Information Systems, 16(4), 479-493, 2007

[38] J.-L. Denis, A. Langley and V. Sergi, "Leadership in the plural", The Academy of Management Annals, vol. 6, no. 1, 211-283, 2012.

[39] L. White, G. Currie and A. Lockett, "Pluralized leadership in complex organisations: exploring the cross-network effects between formal and informal leadership relations", The Leadership Quarterly, 27 (2016), 280-297, 2016

[40] K. Otter and D. Paxton, "A journey into collaborative leadership: moving toward innovation and adaptability", New Directions for Adult and Continuing Education, no 156, 2017. 
European Journal of Business and Management Research www.ejbmr.org

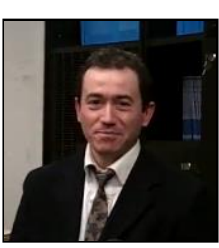

Luigi Gentili is an Italian sociologist and author $\mathrm{He}$ is a professor of media sociology at the Pantheon Institute, Design \& Technology of Rome and president of CEIMA, Centre for the Study of Managerial Innovation. His main interests cover economic sociology, focusing on leadership strategies, organisational development, and brand management. He has collaborated with various business schools, enterprises networks and professional associations. As a speaker, he often gives speeches at conferences and conventions for prestigious institutions. He also published numerous monographs and essays, including "Economia liquida" (Liquid economy) and "Ripartire dalla crescita" (Restarting from growth), recently published by Armando Editore. 